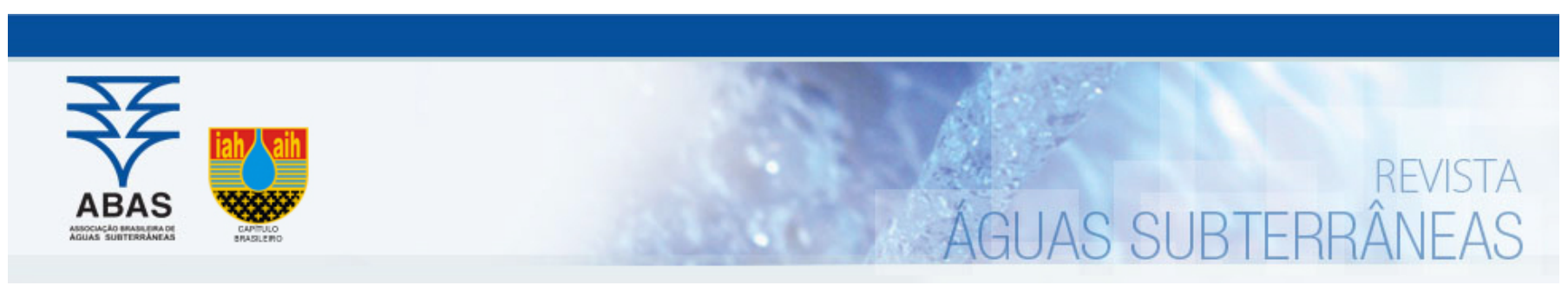

Artigos

\title{
Análise de parâmetros físicos, químicos e microbiológicos de poços de monitoramento em área aplicada com vinhaça
}

\author{
Physical, chemical, and microbiological parameters analysis from monitoring \\ wells of an area with vinasse application
}

\author{
Ana Carolina Correia de Oliveira Gomes ${ }^{1}$; Laércio Alves de Carvalho1; Yzel Rondon Súarez ${ }^{1}$; Elaine Novak; Rodrigo Martins Moreira1 ${ }^{\circledR}$ \\ 1 Universidade Estadual de Mato Grosso do Sul (UEMS), Dourados, MS

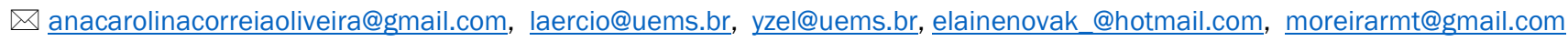

\section{Palavras-chave:}

Impacto ambiental.

Recursos hídricos.

Lençol freático.

Contaminação.

Hidrogeologia.

Resumo

A vinhaça é um subproduto no processo de produção de açúcar e álcool e é comumente aplicada nos canaviais como fertilizante mineral, contudo apresenta alto potencial de contaminação para o solo, a água superficial e subterrânea. Este trabalho visa avaliar a qualidade da água subterrânea através do monitoramento de alguns parâmetros físico-químicos e microbiológicos em poços de monitoramento existentes em áreas de cana-de-açúcar irrigadas com vinhaça. Para isto foram analisados 14 parâmetros de qualidade da água em 17 poços de monitoramento distribuídos em área de 10.138,23ha de aplicação de vinhaça de uma usina de açúcar e álcool no estado do Mato Grosso do Sul, Brasil. Os parâmetros analisados foram: condutividade, cor aparente, DB0520, fostato total, nitrato, nitrito, nitrogênio amoniacal total, nitrogênio total Kjeldahl, OD, pH, sólidos totais, turbidez e coliformes totais. As análises ocorreram semestralmente no período de 2009 a 2012. Através da Análise de Componentes Principais, aplicada separadamente às amostragens nos períodos seco e chuvoso, foi constatado que os poços se diferenciam pelo tempo de aplicação de vinhaça, sugerindo que os parâmetros avaliados de qualidade da água estão sendo influenciados pela aplicação de vinhaça. Os poços de monitoramento podem ser fontes de contaminação de água subterrânea, porém no presente estudo não foram observados valores que alterassem a qualidade da água subterrânea possivelmente pela capacidade de depuração do solo, pela aplicação de vinhaça adequadamente e correta construção dos poços seguindo a NBR n 15495-1:2007.

Abstract

Keywords

The vinasse is a spinoff of sugar and alcohol production and is generally applied as mineral fertilizer in sugarcane fields, however have high potential soil contaminate, superficial water and groundwater. This article aims to evaluate the water quality monitoring some physical, chemical and microbiological parameters in monitoring existing in sugarcane areas irrigated with vinasse. For this was analisated 14 water quality parameters in 17 monitoring wells distributed in an area of 10.138,23ha of vinasse application in a sugar and alcohol company in the state of Mato Grosso do Sul, Brazil. The parameters analyzed were conductivity, apparent color, DB0520, COD, Total phosphate, nitrate, nitrite, ammonia Total nitrogen, total Kjeldahl nitrogen, DO, pH, total solids, turbidity, total and fecal coliforms. The analyzes were conducted semi-annually in the period 2009-2012. Through Principal Component Analysis, applied separately to samples in the dry and rainy periods, it was found that the wells are differentiated by the time of application of vinasse, suggesting that the evaluated parameters of water quality are being influenced by the application of vinasse. The monitoring wells may be sources of contamination of groundwater, but in the present study was not observed values to alter the quality of groundwater possibly the ability to debug the soil, the properly application of vinasse and proper construction of wells following the NBR $n^{\circ} 15495-1: 2007$.

DOI: http://dx.doi.org/10.14295/ras.v32i2.29105

\section{INTRODUÇÃO}

A vinhaça é um dos subprodutos da indústria sucroalcooleira, quando lançada em quantidade adequada no solo, pode promover melhoria em sua fertilidade, uma vez que é rica em água e nutrientes (de OLIVEIRA BORDONAL, 2018). Porém, quando utilizada sem critérios adequados e em altas taxas, pode ocasionar a salinização do solo, alterar suas condições naturais de fertilidade, atingir e contaminar as águas subterrâneas (CETESB, 2012; CHRISTOFOLETTI et al., 2013), e acarretar uma alta concentração de matéria orgânica e de metais, como amônia, magnésio, alumínio, ferro e cloreto (COPAM, 2011; PIACENTE, 2005).

Os efeitos da alteração hídrica pela vinhaça prejudicam o abastecimento de água para uso doméstico, industrial e econômico, sendo assim, em 1978 o Ministério do Interior publicou a portaria MINTER $\mathrm{n}^{\circ} 323$, de 29.11.78, proibindo o lançamento direto ou indireto da vinhaça em qualquer corpo hídrico. De acordo com Corazza (2001), 
a solução encontrada foi depositar o resíduo em áreas de sacrifício, que acabaram se tornando um enorme passivo ambiental.

Para evitar a contaminação, a aplicação de vinhaça deve levar em consideração as características do solo e suas necessidades nutricionais (de MELO et al., 2018). No Estado de Mato Grosso do Sul, a Secretaria do Estado de Meio Ambiente e do Desenvolvimento Econômico (SEMADE) por meio da Resolução SEMADE No 19 DE 02/09/2015, estabelece critérios e procedimentos para armazenamento, distribuição e aplicação no solo de vinhaça in natura e águas residuárias. 0 cálculo para dosagem de aplicação deverá seguir as exigências do Art. 10 da supracitada Resolução, onde, tais doses “deverão ser calculadas em função da necessidade nutricional da cultura e da recuperação da fertilidade do solo em relação às concentrações do nutriente potássio $(K)$ determinadas nas análises de solo".

Se a aplicação de vinhaça nos canaviais não for homogênea e/ou exceder a dosagem máxima estabelecida as características do solo, elementos presentes em sua composição, como o nitrogênio (na forma de nitrato), potássio e outros podem ser percolados e/ lixiviados, contaminando as águas subterrâneas e superficiais.

A contaminação da água subterrânea ocorre quando os poluentes superam a sua proteção natural. Esta vulnerabilidade dependerá das características litológicas e hidrogeológicas dos estratos que separam o aquífero do contaminante, e dependerá também dos gradientes hidráulicos que determinam os fluxos e o transporte das substâncias contaminantes (MINDRISZ, 2006).

A qualidade da água de determinado local é consequência de fatores naturais e antrópicos, mas de acordo com o uso e manejo do local, pode-se admitir uma qualidade diferente do que o recurso hídrico apresenta (VON SPERLING, 2005). Assim, para avaliar e monitorar a qualidade de águas é de extrema importância à utilização de parâmetros de qualidade de água, que servem tanto para mensurar sua sadia qualidade quanto as interferências antrópicas no meio (MOLOZZI et al., 2006) que acarretam em sua contaminação.

A utilização destes parâmetros permite o diagnóstico, caracterizando-se como ferramentas preventivas e monitoramento contínuo da qualidade ambiental provendo suporte à tomada de decisão (FREGOLENTE et al., 2018).

Vários parâmetros de qualidade da água traduzem as características do ambiente, alguns deles possuem valores padrões estabelecidos nas Resoluções CONAMA n 357/05 e n³96/08 e que servem de comparação das condições de qualidade da água. Entre os parâmetros comumente utilizados se destacam a temperatura, turbidez, condutividade específica, pH (potencial hidrogeniônico), nitrogênio, fósforo, demanda bioquímica de oxigênio (DBO), oxigênio dissolvido (OD), sólidos, resíduos, coliformes fecais e termotolerantes (VON SPERLING, 2005).
Neste âmbito, o objetivo dos pesquisadores deste trabalho foi avaliar a influência da aplicação de vinhaça na qualidade de água do lençol freático em uma área cultivada com cana-de-açúcar.

\section{OBJETIVOS}

O objetivo geral do trabalho foi avaliar a influência da aplicação de vinhaça na qualidade de água do lençol freático em uma área cultivada com cana-de-açúcar através do estudo sistemático de alguns parâmetros físico-químicos e microbiológicos em poços de monitoramento. Os objetivos secundários foram: comparar e analisar os parâmetros hidrobiológicos dos dezessete poços de monitoramento em área de fertirrigação com vinhaça no decorrer de três anos e meio; analisar a qualidade da água subterrânea através do comparativo dos parâmetros hidrobiológicos dos poços de monitoramento com os seus valores máximos permitidos de acordo com a resolução CONAMA n 396, de 03 de Abril de 2008.

\section{MATERIAIS E MÉTODOS}

\section{1 Área de estudo}

O trabalho foi conduzido no município de Rio Brilhante, Estado de Mato Grosso do Sul, demarcado pelas coordenadas $21^{\circ} 44^{\prime} 05.1977^{\prime \prime}$ de latitude sul e 54⒉'55.7710" de longitude oeste. O solo é classificado como Latossolo Vermelho Eutrófico típico, de textura argilosa (EMBRAPA, 2006), característico de formações geológicas basálticas de formação Serra Geral (IMASUL, 2010). Os poços estão situados no Sistema Aquífero Serra Geral e fazem parte da Bacia Hidrográfica do Rio Paraná, Sub bacia do Rio Ivinhema (IMASUL, 2012). De acordo com o sistema de classificação köppen (Cwa), o clima é caracterizado como mesotérmico úmido, verões quentes e invernos secos.

Os locais de estudo consistiram em duas áreas, sendo uma com aplicação de vinhaça desde 2009 (representada pelos poços de monitoramento 01 a 12) e uma com aplicação de vinhaça a partir de 2011 (representada pelos poços de monitoramento 13 a 17). As áreas de estudo receberam aplicação de vinhaça através da aspersão por canhões que a captam em canais secundários e correspondeu a um total de $10.138,23$ ha no ano de 2011. Ao todo, foram avaliados 16 poços de monitoramento, pois o poço de monitoramento 01 é seco, em ambos os períodos, e não foi incluído na análise.

A quantidade e localização dos poços (figura 1) foram definidas através de exigência técnica no licenciamento ambiental do empreendimento pelo IMASUL - Instituto de Meio Ambiente de Mato Grosso do Sul, que é o órgão ambiental estadual responsável pela fiscalização e controle ambiental. Os poços de monitoramento foram construídos de acordo com a NBR (Norma Brasileira) da Associação Brasileira de Normas Técnicas (ABNT) n 15495-1:2007 (figura 2) em toda a extensão e apresentam profundidade média de cinco metros. 
Figura 1 - Área de aplicação de vinhaça

\section{Pontos de Coleta com aplicação de vinhaça a partir de 2009 e a partir de 2011}

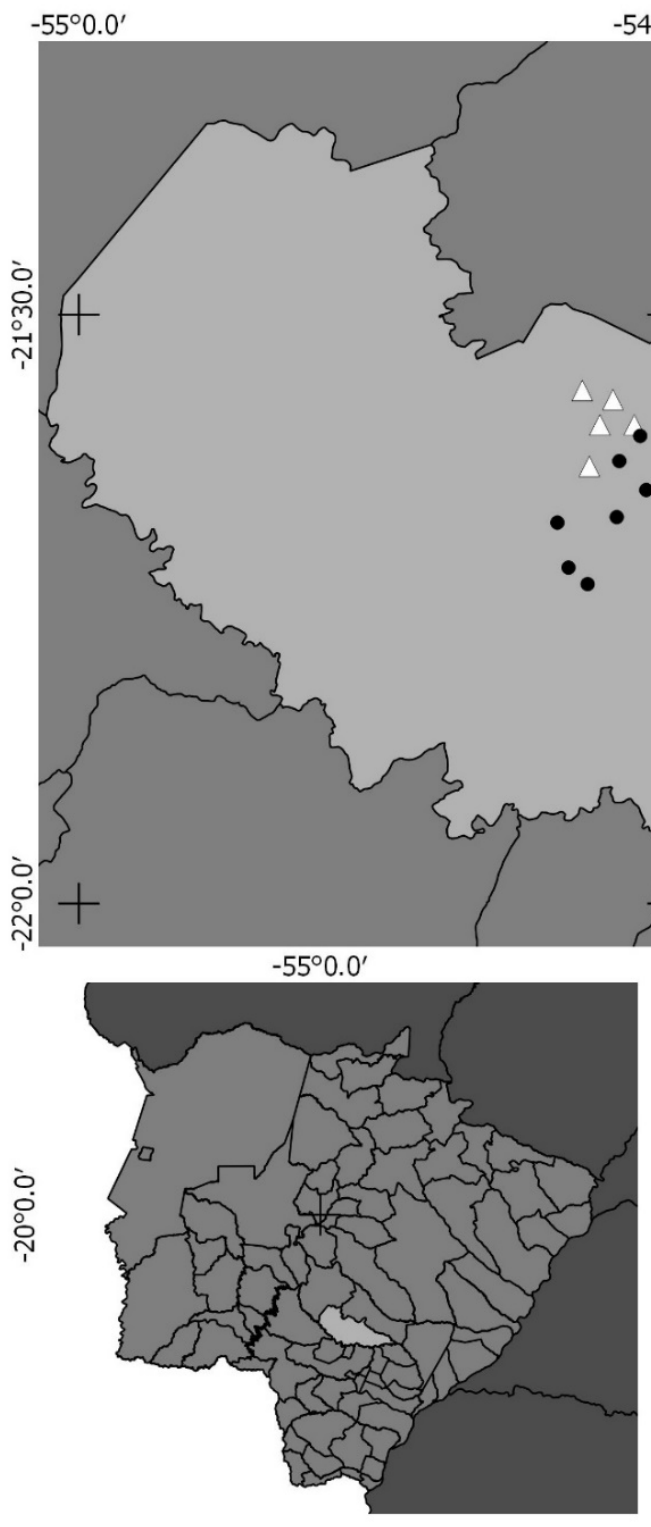

\section{Legenda}

- Pontos de coleta com aplicação desde 2009 Pontos de coleta com aplicação desde 2011 Município de Rio Brilhante

Estado de Mato Grosso do Sul Brasil

Fonte: Os autores (2018) $-54^{\circ} 30.0^{\prime}$

$-54^{\circ} 0.0^{\prime}$
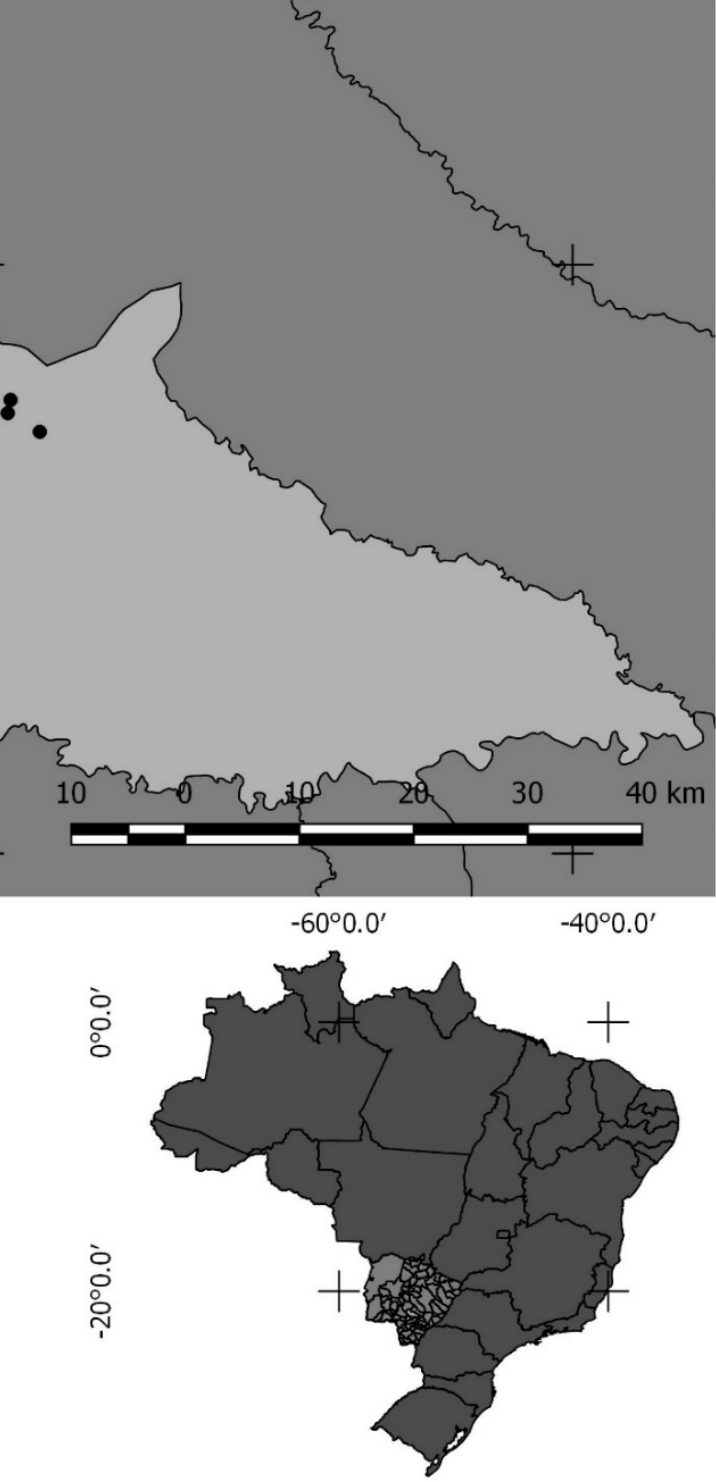

Fonte da base cartográfica: IBGE, 2018. Datum: SIRGAS 2000.

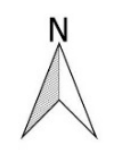


Figura 2 - Foto esquemática de um dos poços de monitoramento construído conforme a NBR n 15495-1:2007.

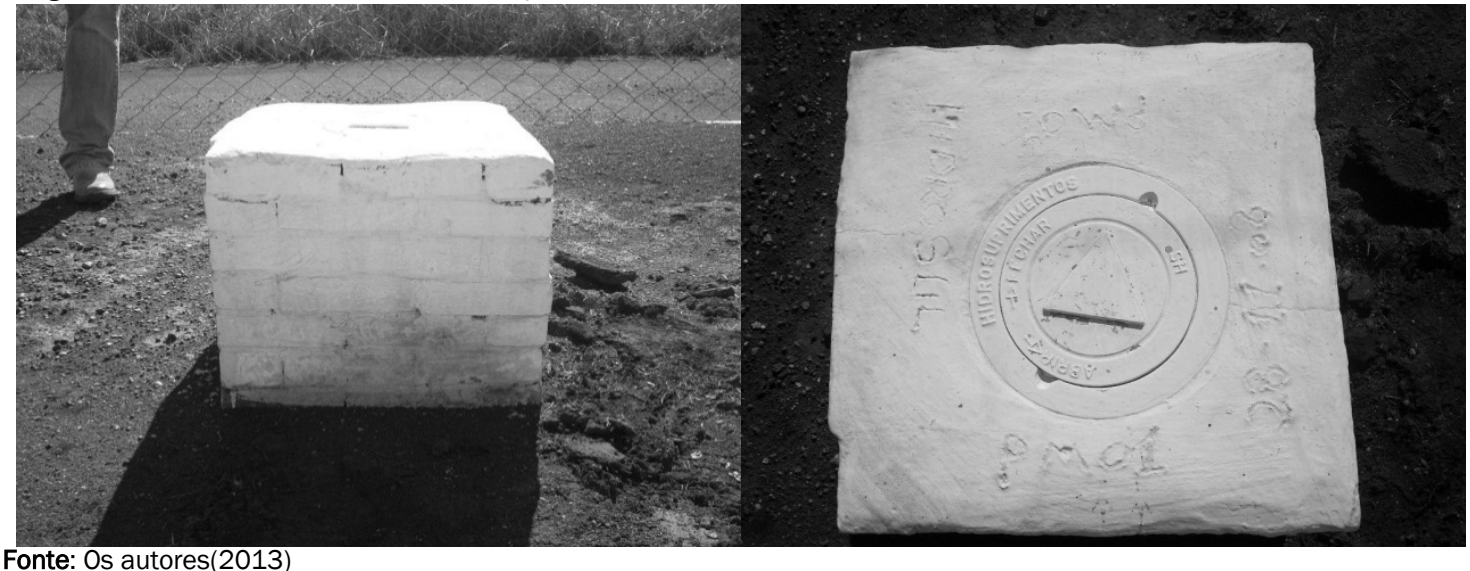

\subsection{Coleta de material e Parâmetros analisados}

As análises das águas subterrâneas foram realizadas semestralmente, através de amostragens simples no período de 2009 à 2012. A água de cada poço foi retirada utilizando um amostrador descartável de água subterrânea (bailer).

Para realizar a captação de água, o bailer foi imerso no poço até ser cheio de água, posteriormente esta água foi despejada, com ajuda de um bico, em um recipiente de alumínio, este procedimento foi realizado até obter o volume de água necessário para realizar as análises. A água foi transferida para frascos esterilizados e identificados e, então, armazenados em recipiente térmico com gelo ( $\mathrm{Fi}$ gura 3$)$.
Os parâmetros analisados foram: condutividade, cor aparente, DBO 5,20 (Demanda Bioquímica de Oxigênio), fosfato total, nitrato, nitrito, nitrogênio amoniacal total, nitrogênio total Kjeldahl, OD (Oxigênio Dissolvido), $\mathrm{pH}$, sólidos totais, turbidez, coliformes totais. Além disso, foi medido o nível estático e profundidade de cada poço tubular profundo.

A metodologia utilizada nos testes laboratoriais foi realizada de acordo com Standard Methods for the Examination of Water and Wastewater (SMEWW), 21st Edition, conforme Tabela 1.

Figura 3 - (A a C)- Coleta de água subterrânea com auxilio de um Bailer. D- Embalagem hermética para armazenamento de água
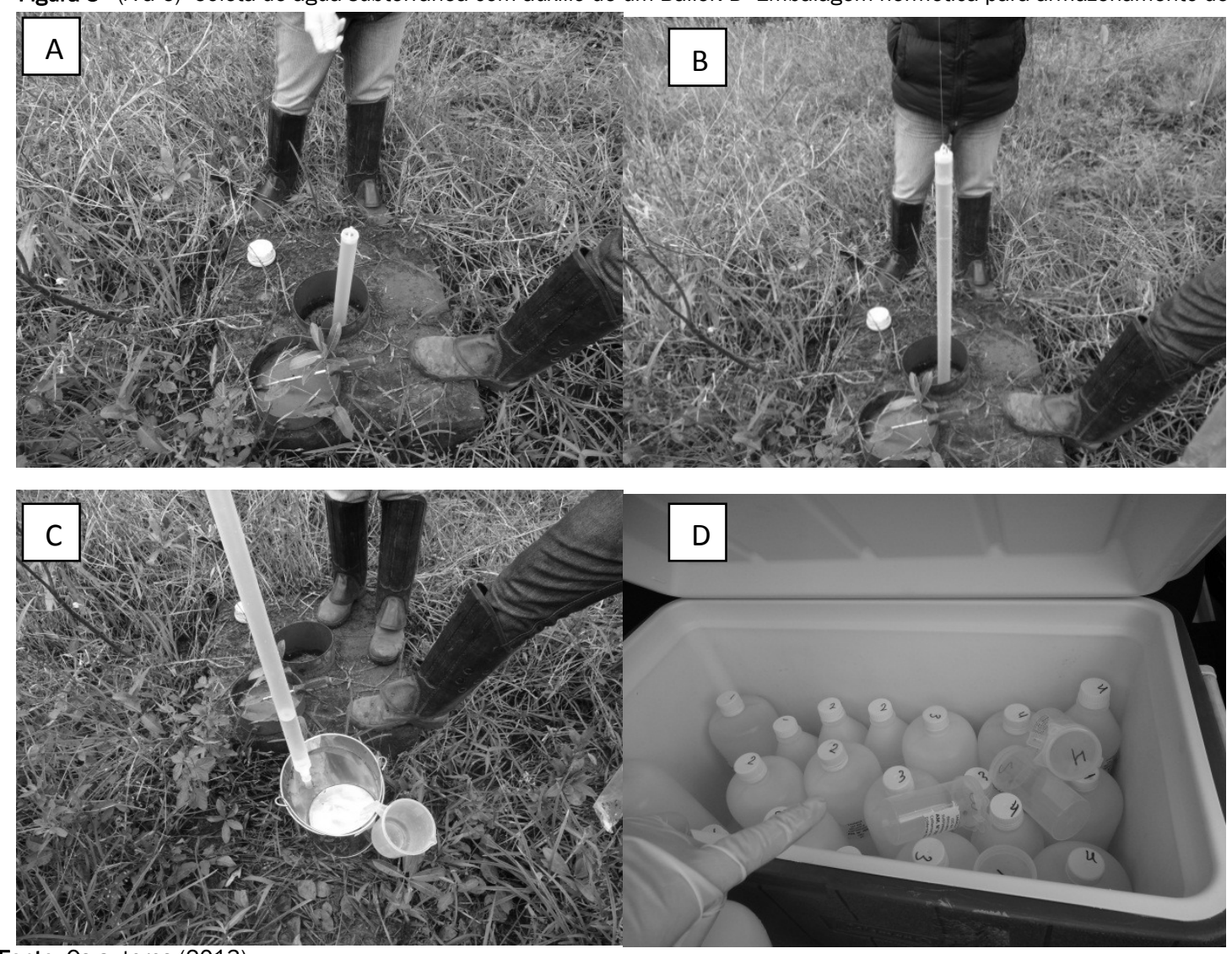

Fonte: Os autores (2013) 
Tabela 1 - Metodologia utilizada nos testes laboratoriais de acordo com Standard Methods for the Examination of Water and Wastewater (SMEWW), 21st Edition.

\begin{tabular}{|c|c|c|c|c|}
\hline Parâmetro & Método & $\begin{array}{l}\text { Limite de detec- } \\
\text { ção }\end{array}$ & Equipamento & Marca \\
\hline Amônia & $\begin{array}{c}\text { SMEWW 4500-NH3 F- Phenate } \\
\text { Method }\end{array}$ & 0,14 mg NH3/L & $\begin{array}{l}\text { Destilador de Nitro- } \\
\text { gênio }\end{array}$ & Tecnal \\
\hline Condutividade & SMEWW 2510 - Laboratory Method & $\begin{array}{c}0,3 \mathrm{uS} / \mathrm{cm} \text { a } 20 \\
\mathrm{mS} / \mathrm{cm}\end{array}$ & $\begin{array}{l}\text { Condutivimetro de } \\
\text { Bancada }\end{array}$ & MSTecnopon \\
\hline DBO & SMEWW 5210 B - 5 Days BOD Test & $2,0 \mathrm{mg} \mathrm{02/L}$ & Incubadora de DBO & Tecnal \\
\hline Fosfato Total & $\begin{array}{l}\text { SMEWW 4500-P E - Ascorbic Acid } \\
\text { Method }\end{array}$ & $0,2 \mathrm{mg} / \mathrm{L}$ & $\begin{array}{l}\text { Cromatografo de } \\
\text { íons }\end{array}$ & Metrohm \\
\hline Nitrato & $\begin{array}{l}\text { SMEWW } 4500 \text { NO3 E - Cadmium Re- } \\
\text { duction Method }\end{array}$ & $0,2 \mathrm{mg} / \mathrm{L}$ & $\begin{array}{l}\text { Cromatografo de } \\
\text { íons }\end{array}$ & Metrohm \\
\hline Nitrito & $\begin{array}{c}\text { SMEWW } 4500 \text { NO2 B - Colorimetric } \\
\text { Method }\end{array}$ & $0,03 \mathrm{mg} / \mathrm{L}$ & $\begin{array}{l}\text { Cromatografo de } \\
\text { íons }\end{array}$ & Metrohm \\
\hline $\begin{array}{l}\text { Nitrogênio total } \\
\text { Kjeldahl }\end{array}$ & $\begin{array}{l}\text { SMEWW 4500-Norg B - Macro- } \\
\text { Kjeldahl Method }\end{array}$ & $0,2 \mathrm{mg} \mathrm{N} / \mathrm{L}$ & $\begin{array}{c}\text { Bloco de Digestão e } \\
\text { Destilador de Nitro- } \\
\text { gênio }\end{array}$ & Tecnal \\
\hline Oxigênio Dissolvido & $\begin{array}{l}\text { SMEWW 4500-O C - Azide Modifica- } \\
\text { tion }\end{array}$ & $\begin{array}{c}0,03 \mathrm{mg} / \mathrm{L} \mathrm{de} \\
\mathrm{O}_{2}\end{array}$ & HI 9146 & Hanna \\
\hline $\mathrm{pH}$ & $\begin{array}{c}\text { SMEWW 4500-H+ - Eletrometric Me- } \\
\text { thod }\end{array}$ & 2 a 12 & $\begin{array}{l}\text { Medidor de pH portá- } \\
\text { til TEC-3P-MP }\end{array}$ & Tecnal \\
\hline $\begin{array}{l}\text { Sólidos dissolvidos } \\
\text { totais }\end{array}$ & $\begin{array}{c}\text { SMEWW } 2540 \mathrm{C} \text { - Total Dissolved } \\
\text { Solids Driedat } 180^{\circ} \mathrm{C}\end{array}$ & $10 \mathrm{mg} / \mathrm{L}$ & $\begin{array}{l}\text { Banho Maria e Ba- } \\
\text { lança }\end{array}$ & $\begin{array}{c}\text { Tecnal (Ba- } \\
\text { nho Maria) e } \\
\text { Shimadzu } \\
\text { (Balança) }\end{array}$ \\
\hline Coliformes totais & $\begin{array}{l}\text { SMEWW } 9223 \text { B - Enzyme Sub- } \\
\text { strate Coliform Test }\end{array}$ & $1 \mathrm{NMP} / 100 \mathrm{~mL}$ & Estufa & Cienlab \\
\hline
\end{tabular}

\subsection{Análise estatística}

Os dados de todos os parâmetros foram analisados separadamente para cada estação (seca e chuvosa) através de uma Análise de Componentes Principais - PCA, utilizando o software vegan, plataforma R (R Core Team, 2017). Também foi realizada análise descritiva para os parâmetros nitrato, nitrito e sólidos totais dissolvidos através do programa estatístico Bioestat (AYRES, 2007). Além disso, os três parâmetros analisados pela analise descritiva foram comparados com os respectivos valores máximos permitidos pela resolução CONAMA $n^{\circ} 396$, de 03 de abril de 2008 que dispõe sobre a classificação e diretrizes ambientais para o enquadramento das águas subterrâneas e dá outras providências.

\section{RESULTADOS E DISCUSSÃO}

Na Tabela 2 são apresentados os valores obtidos das medidas das análises descritivas para os parâmetros, nitrato, nitrito e sólidos totais dissolvidos a fim de visualizar o comportamento geral dos dados e identificar possíveis valores discrepantes. Os valores de média e mediana para os três parâmetros não foram semelhantes, o que indica uma variação não normal dos dados, que pôde ser confirmada através do teste estatístico de Kruskal-Wallis ( $p>0,05)$.

Os valores de nitrato apresentaram alta variabilidade, excetuandose o período chuvoso do ano de 2009 que apresentou médio coeficiente de variação. 0 parâmetro nitrito também apresentou coeficientes de variação alto e baixo, para os períodos de 2009 seco e 2010 chuvoso, respectivamente, e para aquele os demais períodos de análises. 0 coeficiente de variação para os sólidos totais dissolvidos foi de média variabilidade no ano de 2009 em período seco, e de alta variabilidade para os demais períodos de coleta.
Em se tratando de requisitos legais, o Estado de Mato Grosso do Sul não dispõe de nenhuma legislação a respeito da exigência de poços de monitoramento em áreas de fertirrigação, mas no ano de 2012 lançou um Termo de Referência para elaboração de estudo de impacto ambiental (EIA), relatório de impacto ambiental (RIMA) e análise de risco de usina sucroenergética. Constam, neste termo, referências, orientações e informações gerais sobre os procedimentos administrativos necessários à regularização do empreendimento.

O referido termo de referência não dispõe especificamente sobre monitoramento de águas superficiais e subterrâneas, porém exige a caracterização dos recursos hídricos. Apesar dos parâmetros solicitados pelo órgão ambiental, muitos deles não possuem valores de referência para comparação na legislação ambiental vigente.

Na resolução CONAMA n ${ }^{\circ} 396$ de 2008, é possível encontrar valores máximos permitidos que levam em consideração o uso da água e o LQP (Limite de Quantificação Praticáveis) que é o valor da menor concentração de uma substância que pode ser determinada quantitativamente com precisão e exatidão pelo método utilizado. Dentre estes parâmetros encontram-se o nitrato, nitrito e sólidos totais dissolvidos.

Os valores máximos permitidos para o nitrato, para consumo humano, dessedentação de animais e recreação, são 10 mgN/L, 90 $\mathrm{mgN} / \mathrm{L}$ e $10 \mathrm{mgN} / \mathrm{L}$, respectivamente. Já os VMP de nitrito são $10 \mathrm{mgN} / \mathrm{L}$ para dessedentação e $1 \mathrm{mgN} / \mathrm{L}$ para os demais usos. Para os sólidos totais dissolvidos é encontrado apenas o valor de referência de $1000 \mathrm{mgN} / \mathrm{L}$ para consumo humano, como pode ser constatado na Tabela 3. 
Tabela 2 - Estatística descritiva

\begin{tabular}{|c|c|c|c|c|c|c|}
\hline Período & 2009 SECO & 2009 CHUVOSO & 2010 CHUVOSO & 2010 SECO & 2011 SECO & 2012 CHUVOSO \\
\hline \multicolumn{7}{|c|}{ Nitrato } \\
\hline Média & 668.9091 & 152 & 51.1 & 111.0909 & 59.8 & 83.8929 \\
\hline Mediana & 366 & 136.5 & 52 & 56 & 48 & 71 \\
\hline Mínimo & 90 & 64 & 5 & 12 & 16 & 4.5 \\
\hline Máximo & 2931 & 296 & 144 & 354 & 137.5 & 280 \\
\hline Desvio Padrão & 871.5098 & 76.6043 & 44.608 & 105.2326 & 37.7046 & 66.5664 \\
\hline CV (\%) & $130.29 \%$ & $50.40 \%$ & $87.30 \%$ & $94.73 \%$ & $63.05 \%$ & $79.35 \%$ \\
\hline \multicolumn{7}{|c|}{ Nitrito } \\
\hline Média & 0.0814 & 0.051 & 0.047 & 0.0818 & 0.0383 & 0.0264 \\
\hline Mediana & 0.075 & 0.04 & 0.04 & 0.07 & 0.02 & 0.02 \\
\hline Mínimo & 0.05 & 0.03 & 0.03 & 0.03 & 0.01 & 0.01 \\
\hline Máximo & 0.165 & 0.14 & 0.11 & 0.21 & 0.18 & 0.09 \\
\hline Desvio Padrão & 0.0326 & 0.0328 & 0.0254 & 0.0613 & 0.0458 & 0.0213 \\
\hline CV (\%) & $40.12 \%$ & $64.34 \%$ & $54.06 \%$ & $74.91 \%$ & $119.41 \%$ & $80.75 \%$ \\
\hline \multicolumn{7}{|c|}{ Sólidos totais dissolvidos } \\
\hline Média & 668.9091 & 152 & 51.1 & 111.0909 & 59.8 & 83.8929 \\
\hline Mediana & 366 & 136.5 & 52 & 56 & 48 & 71 \\
\hline Mínimo & 90 & 64 & 5 & 12 & 16 & 4.5 \\
\hline Máximo & 2931 & 296 & 144 & 354 & 137.5 & 280 \\
\hline Desvio Padrão & 871.5098 & 76.6043 & 44.608 & 105.2326 & 37.7046 & 66.5664 \\
\hline CV (\%) & $130.29 \%$ & $50.40 \%$ & $87.30 \%$ & $94.73 \%$ & $63.05 \%$ & $79.35 \%$ \\
\hline
\end{tabular}

Fonte: Os autores (2013)

Tabela 3 - Valores máximos permitidos de alguns parâmetros em água subterrânea de acordo com o seu uso.

\begin{tabular}{|c|c|c|c|c|}
\hline & \multicolumn{4}{|c|}{ Usos Preponderantes da Água } \\
\hline & $\begin{array}{l}\text { Consumo } \\
\text { Humano }\end{array}$ & $\begin{array}{c}\text { Dessedentação } \\
\text { de animais }\end{array}$ & Irrigação & Recreação \\
\hline Parâmetros & \multicolumn{4}{|c|}{$\mathrm{mg} / \mathrm{L}$} \\
\hline Nitrato (expresso em N) & 10 & 90 & - & 10 \\
\hline Nitrito (expresso em N) & 1 & 10 & 1 & 1 \\
\hline Sólidos totais dissolvidos (STD) & 1000 & - & - & - \\
\hline
\end{tabular}

Os dados de nitrato obtidos em todos os poços de monitoramento ao longo do tempo de coletas ficaram bem abaixo dos valores máximos permitidos estabelecidos pela resolução CONAMA n 369/08 (Figura 4), corroborando com os valores encontrados por Rolim et al. (2013) com média de $0,17 \mathrm{mg} / \mathrm{L}$ de nitrato.

Por possuírem valores extremamente baixos, menores ou iguais a $0,01 \mathrm{mgN} / \mathrm{L}$, os valores de nitrato no período de 2009 seco dos poços de monitoramento 04, 08, 09, 11 e 12 não aparecem no gráfico.

Ao analisar as figuras 5 e 6 é possível perceber que os poços de monitoramento 13 à 17 possuem apenas valores dos anos de 2011 e 2012. Isto ocorre porque as áreas em que estão inseridos começaram a receber aplicação de vinhaça somente em 2011. Nota-se também que o poço de monitoramento 05 não possui os valores dos parâmetros para os períodos 2011 seco, 2009, 2010 e 2012 chuvosos, pois nestes períodos houve impedimentos de acesso ao coletor (bailer).

O menor valor máximo permitido para nitrito estabelecido pela resolução mencionada é de $1 \mathrm{mgN} / \mathrm{L}$ referente aos usos para consumo humano, irrigação e recreação. É possível afirmar que nenhum dos poços ultrapassou os valores de referência em nenhum dos anos de aplicação.

Os maiores valores obtidos nas coletas foram encontrados nos poços de monitoramento 06 e 10 no período seco do ano de 2010, cujos valores são de 0,21 mgN/L e 0,19 mgN/L, respectivamente. 
Figura 4 - Valores de nitrato em 16 pontos de coleta no período de 2009-2012

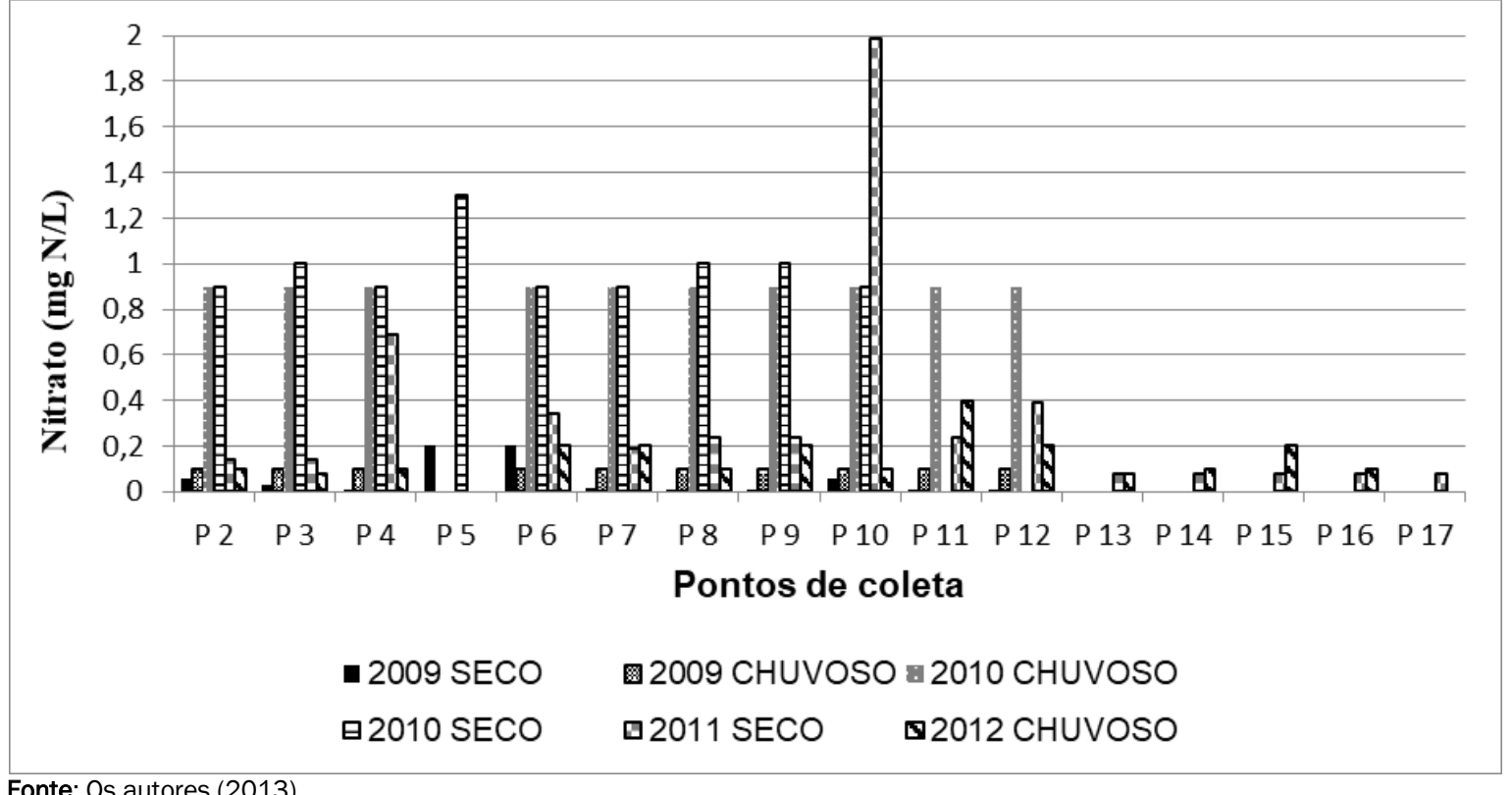

Fonte: Os autores (2013)

Figura 5 - Valores de nitrito em 16 pontos de coleta no período de 2009-2012

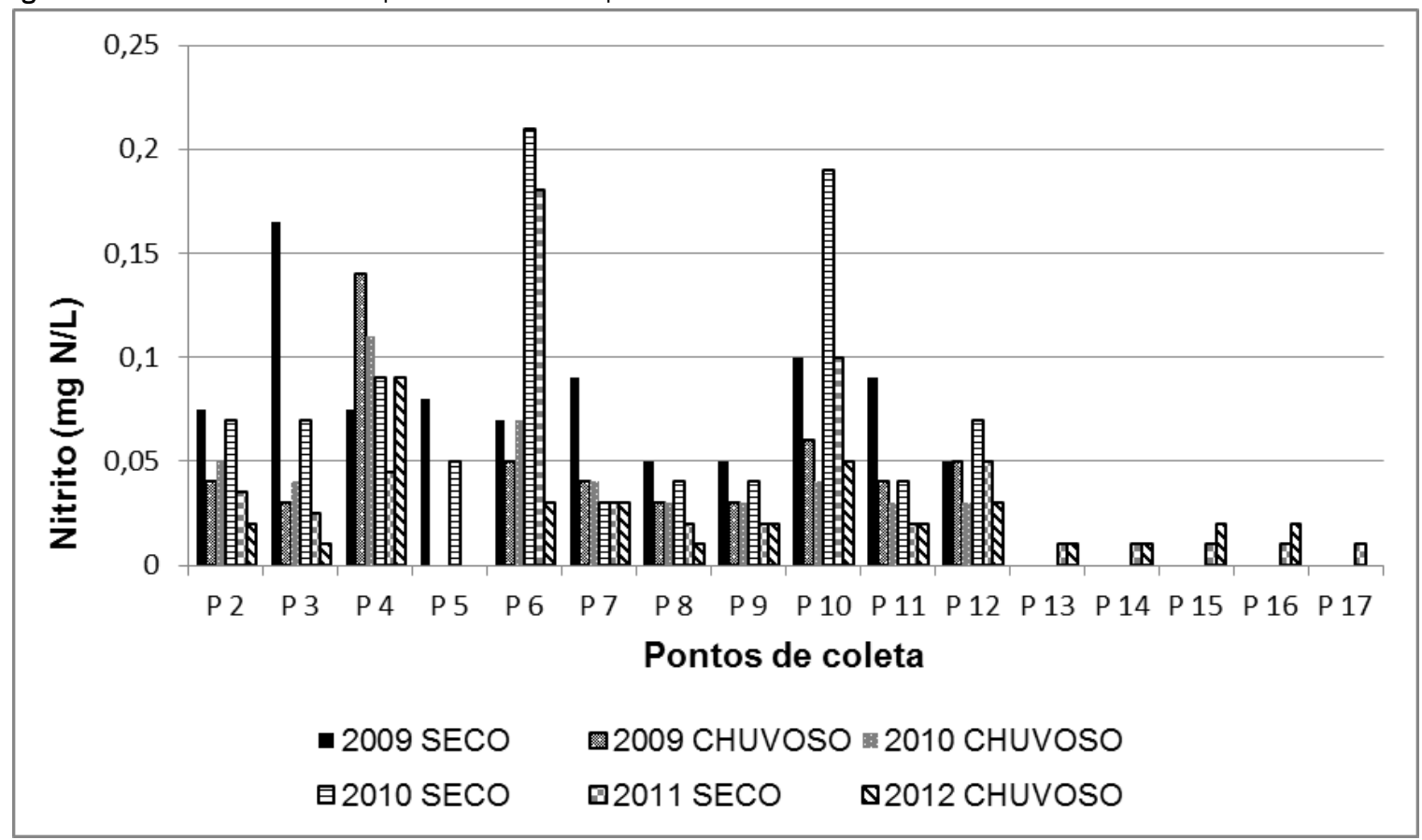

Fonte: Os autores (2013) 
Figura 6 - Valores de sólidos totais dissolvidos em 16 pontos de coleta no período de 2009-2012

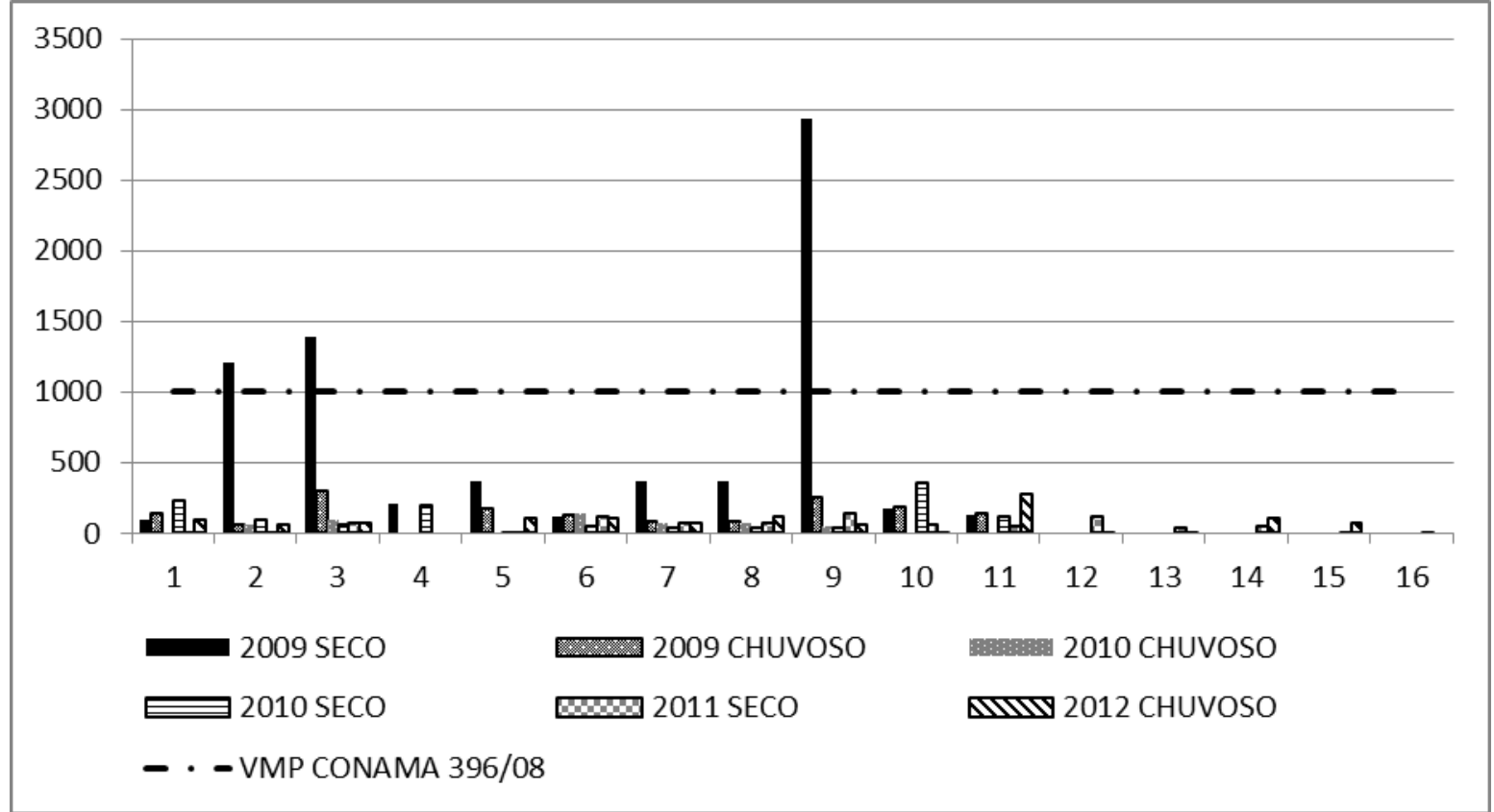

Fonte: Os autores (2013)

Além de terem sido encontrados valores baixos para os parâmetros nitrato e nitrito é importante salientar que a vinhaça não é a única fonte deste elemento na água subterrânea, efluentes domésticos e industriais também podem contaminar a água subterrânea por nitrato (WAKIDA \& LERNER, 2005). Esta contaminação pode ocorrer em áreas adjacentes e através do fluxo de água subterrâneo contaminar outras áreas.

Ao analisar os valores de sólidos totais dissolvidos obtidos e o valor máximo permitido de acordo com a resolução CONAMA n 369/08 foi possível constatar que no período seco do ano de 2009 os poços de monitoramento 04, 05 e 10 ficaram acima do valor de referência, destacando-se o poço 10 com concentração de $2.931 \mathrm{mg} / \mathrm{L}$, quase o triplo do permitido.

Rolim et al. (2013), obtiveram elevadas concentrações de sólidos totais dissolvidos e relacionaram tais valores a longos períodos de disposição de vinhaça no solo e pelo fato dos sólidos totais dissolvidos serem altamente dissolutos, lixiviando mais facilmente e atingindo o lençol de água. Entretanto, não se pode atribuir esta concentração pela aplicação de vinhaça, pois esta coleta foi realizada no período em que se iniciou a fertirrigação, além disso, nos anos posteriores a aplicação continuou e os valores de sólidos totais dissolvidos para os mesmos poços apresentaram uma queda considerável. Os valores encontrados provavelmente estão relacionados a atividades anteriores que eram exercidas nos locais e em seu entorno. Além disso, o valor máximo permitido da resolução está relacionado ao consumo humano, sendo este uso o mais restritivo de todos.

Ao analisar os valores dos parâmetros que possuem valores de referencia, foi possível constatar que a aplicação de vinhaça pode alterar a composição de água subterrânea, porém não chegaram alterar a qualidade na mesma, corroborando com Brito et al. (2007) que ao estudar três tipos de solo, classificados como Nitossolo Háplico, Argissolo Amarelo e Espodossolo Cárbico tratados com vinhaça em diferentes concentrações, puderam constatar que apesar das diferentes características de cada classe de solo estudado, todos possuem elevado poder de retenção da vinhaça diminuindo a possibilidade de contaminação do lençol freático.

Lyra et al. (2003), relataram a diminuição nas concentrações de DBO em água subterrânea em área de cana-de-açúcar com aplicação de vinhaça. Segundo os autores, esta redução foi associada a capacidade do solo em reter matéria orgânica.

Apesar de o potássio ser o elemento de maior concentração na vinhaça, não foi avaliado neste estudo por falta de repetições de análises. Ressaltando que todos os parâmetros foram analisados conforme orientação do órgão ambiental, alguns parâmetros poderiam ser adicionados às análises e outros suprimidos, como o parâmetro de coliformes que não tem relação direta com a aplicação de vinhaça.

$\mathrm{Na}$ análise de componentes principais (PCA), a soma da variabilidade retida nos componentes explicou $56,1 \%$ da variabilidade original dos dados referentes aos dados do período chuvoso, sendo que o primeiro eixo explicou $37,5 \%$ da variação nos dados e foi influenciado principalmente pela cor, nitrogênio amoniacal, nitrato e DBO, enquanto o segundo eixo explicou $18,6 \%$ da variação nos dados e refletiu, principalmente, os valores de coliformes totais, nitrogênio total e $\mathrm{pH}$. Para o período seco, a soma da variabilidade retida nos dois primeiros eixos explicou $51,4 \%$ da variabilidade original dos dados, sendo o primeiro eixo explicou $35,4 \%$ da variação nos dados influenciado principalmente pela concentração de nitrogênio total e cor, enquanto o segundo eixo explicou $16 \%$ nos dados e refletiu principalmente os dados de turbidez e sólidos totais dissolvidos (Tabela 4 e Figura 7). 
Tabela 4 - Resultados da Análise de Componentes Principais para as variáveis de qualidade da água nos períodos seco e chuvoso em poços de monitoramento. Variáveis com loading maior que 0,3 foram marcadas em negrito

\begin{tabular}{lcc|cc}
\hline & \multicolumn{2}{c}{ Período Seco } & \multicolumn{2}{c}{ Período Chuvoso } \\
\hline Parâmetros analisados & Eixo 1 & Eixo 2 & Eixo 1 & Eixo 2 \\
Nível Estático & 0,163 & $-0,059$ & 0,233 & $-0,027$ \\
Condutividade & 0,117 & $-0,358$ & 0,011 & 0,266 \\
Cor & 0,387 & 0,153 & 0,381 & 0,178 \\
Demanda Bioquímica de Oxigênio & $-0,307$ & $-0,241$ & $-0,339$ & 0,179 \\
Fosfato & 0.307 & 0,215 & $-0,004$ & 0,185 \\
Nitrato & $-0,350$ & 0,296 & $-0,373$ & $-0,013$ \\
Nitrito & $-0,326$ & 0,331 & $-0,268$ & 0,174 \\
Nitrogênio Amoniacal & $-0,083$ & $-0,079$ & 0,359 & 0,257 \\
Nitrogênio total & $-0,399$ & 0,033 & 0,229 & 0,421 \\
Oxigenio Dissolvido & 0,205 & 0,221 & 0,267 & $-0,227$ \\
pH & 0,115 & $-0,250$ & 0,024 & 0,397 \\
Sólidos Totais Dissolvidos & $-0,266$ & 0,388 & $-0,246$ & 0,353 \\
Turbidez & 0,229 & 0,467 & 0,341 & 0,223 \\
Coliformes totais & $-0,213$ & $-0,234$ & $-0,212$ & 0,416 \\
\% de explicação dos eixos & 35,4 & 16,0 & 37,5 & 18,6 \\
\hline Fonte: Os autores (2018) & & &
\end{tabular}

Fonte: Os autores (2018)

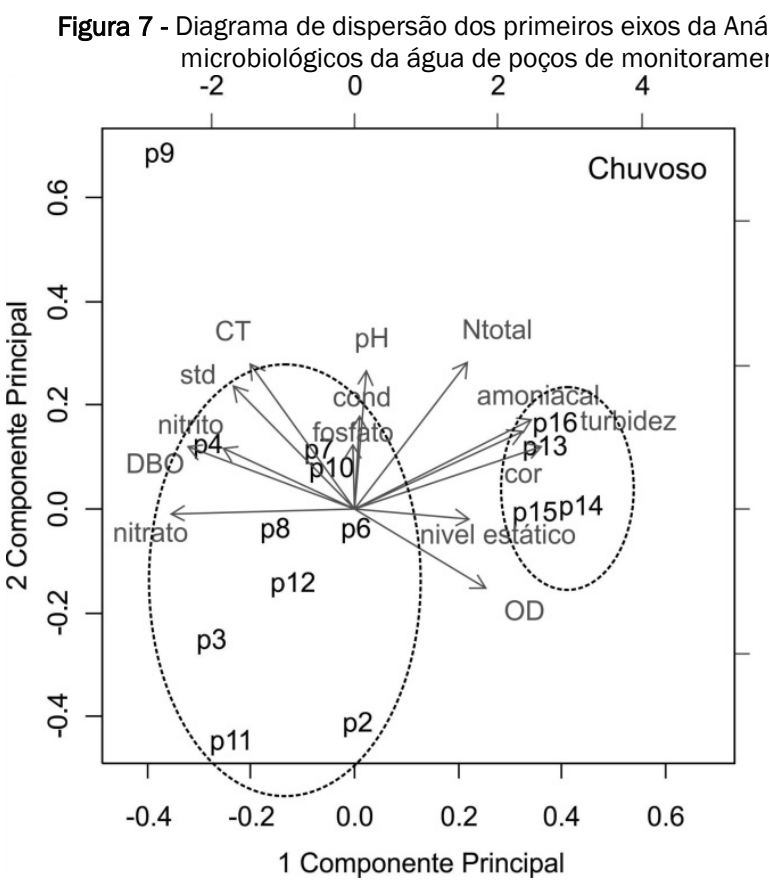

Fonte: Os autores (2013)

Para ambas os períodos (seco e chuvoso) observamos que os poços em área que receberam maior fertirrigação apresentaram maiores valores de demanda bioquímica de oxigênio, maior concentração de nitrato, nitrito e nitrogênio total (loadings negativos) enquanto aqueles com menor fertirrigação apresentaram maiores valores de cor e concentração de fostato, sendo estas variáveis importantes no primeiro eixo da analise de componentes principais.

Desta forma, em ambas as estações foi constatada uma clara separação dos poços de monitoramento de acordo com o tempo de aplicação de vinhaça. Poços que receberam menor quantidade de aplicação de vinhaça diferenciaram de poços com maior tempo de aplicação, corroborando com o trabalho de Ludovice (1997) que observou que o tempo interfere no processo de contaminação. 0 autor concluiu que em decorrência de longos períodos de condução de vinhaça, o solo tem o seu poder de depuração comprometido aumentando assim, a probabilidade da vinhaça atingir e contaminar lençóis de água subterrâneos.

Pereira et al. (2012), ao estudarem o subsolo de um tanque de aplicação de vinhaça sem impermeabilização que funcionou por 14 
anos (do ano de 1980 a 2004), constataram que lixiviados de vinhaça estão presentes em solo areno silte-argiloso, mesmo anos após a interrupção da aplicação de vinhaça. Segundo os autores, os ensaios de lixiviação visaram identificar quais elementos foram prontamente solúveis e geoquimicamente reativos com a água que percola e modifica a composição físico-química das águas subterrâneas, e concluíram que o aumento da concentração de potássio em profundidade é um indicativo do alcance da vinhaça no subsolo e em água subterrânea, assim como Gloeden (1994), que também observou que a vinhaça atingiu a água subterrânea evidenciada pela alteração nos valores dos parâmetros avaliados através de análises químicas ao instalar poços de monitoramento na zona saturada do solo.

Ao estudar dez poços de monitoramento em uma área de cultivo de cana-de-açúcar circunvizinha à lagoa de distribuição de vinhaça, Rolim et al. (2013), concluíram que o armazenamento da vinhaça na lagoa de distribuição alterou a maioria dos parâmetros estudados.

Analisando os dados obtidos pela PCA, observamos que os locais que receberam menor quantidade de vinhaça, poços de monitoramento 13 a 16, apresentaram maior grau de similaridade entre si. Este conjunto de poços é caracterizado por maiores valores de nitrogênio total, nitrogênio amoniacal, turbidez, cor, OD, níveis estáticos e menores valores de nitrato, nitrito, DBO, sólidos totais dissolvidos e coliformes totais. Os valores de nitrato observados neste trabalho corroboram com os encontrados por Gloeden (1994), que encontraram baixa concentração de nitrato em água subterrânea. Os demais pontos de coleta apresentaram menores valores das variáveis mencionadas.

Ao analisar a distribuição dos poços de monitoramento, observamos que o poço 09 se diferenciou dos demais em ambas as estações do ano, se comportando como um outlier (ponto discrepantes em relação à distribuição dos demais dados), respondendo aos resultados dos valores de condutividade elétrica, DBO e concentração de coliformes totais com valores muito superiores aos demais poços analisados (Figura 7).

\section{CONCLUSÕES}

Foi possível observar que, tanto no período chuvoso quanto no período seco, a maior variação dos parâmetros está relacionada com a quantidade de aplicações de vinhaça. Os poços que receberam menor quantidade de aplicações de vinhaça (poços de monitoramento 13 a 17) apresentaram maior grau de similaridade entre si e dissimilaridade com os demais, contendo maiores valores de OD um dos principais parâmetros de qualidade de água.

No estado do Mato Grosso do Sul não há legislação ambiental específica que norteie a aplicação de vinhaça e a forma de monitoramento em área de cana-de-açúcar, por outro lado a resolução CONAMA n 396/08 não é adequada para avaliação de efeitos da vinhaça nesses ambientes, pois não está subdividida em classes de qualidade, ou seja, águas subterrâneas naturais podem apresentar valores maiores do que os valores máximos permitidos de acordo com o uso.

Os poços de monitoramento podem ser fontes de contaminação de água subterrânea, porém no presente estudo não foram observados valores que alterassem a qualidade da água subterrânea possivelmente pela capacidade de depuração do solo, pela aplicação de vinhaça adequadamente e correta construção dos poços seguindo a NBR $n^{\circ}$ 15495-1:2007.

Qualquer atividade realizada irá causar alteração no meio ambiente em que está inserida como é o caso da aplicação de vinhaça, porém foi possível constatar através deste trabalho que o plano de aplicação de vinhaça está suprindo a necessidade da cultura, sem contaminação da água subterrânea.

\section{REFERÊNCIAS}

ASSOCIAÇÃO BRASILEIRA DE NORMAS TÉCNICAS - ABNT. NBR 154951:2007 - Poços de monitoramento de águas subterrâneas em aquíferos granulares - Parte 1: Projeto e construção.. Rio de Janeiro, 2007.

APHA - American Public Health Association; AWWA - American Water Works Association; WEF - Water Environment Federation. Standard methods for the examination of water and wasterwater. 21st ed. Washington, DC.: American Public Health Association, 2005.

AYRES, M., AYRES JÚNIOR, M., AYRES, D.L. \& SANTOS, A.A. 2007. BIOESTAT - Aplicações estatísticas nas áreas das ciências bio-médicas. Ong Mamiraua. Belém, PA. Disponível em: <

http://www.mamiraua.org.br/pt-br/downloads/programas/bioestat-versao53/>. Acesso em: 05 jun. 2014.

BRITO, Fabio L. et al . Qualidade do percolado de solos que receberam vinhaça em diferentes doses e tempo de incubação. Rev. bras. eng. agríc. ambient., Campina Grande, v. 11, n. 3, jun. 2007. Disponível em <http://www.scielo.br/scielo.php?script=sci_arttext\&pid=S1415$43662007000300012 \&$ lng=pt\&nrm=iso>.Acesso em 02 jul. 2013. http://dx.doi.org/10.1590/S1415-43662007000300012.

CETESB - COMPANHIA AMBIENTAL DO ESTADO DE SÃO PAULO. Disponível em: <http://www.cetesb.sp.gov.br/>. Acesso em: 15 jan. 2013.

CETESB - COMPANHIA AMBIENTAL DO ESTADO DE SÃO PAULO. Norma Técnica P4.231- Vinhaça - Critérios e Procedimentos para Aplicação no solo agrícola. Diário Oficial do Estado de São Paulo, 13 fev. 2015.

CHRISTOFOLETTI, C. A., ESCHER, J. P., CORREIA, J. E., MARINHO, J. F. U., FONTANETTI, C. S. Sugarcane vinasse: environmental implications of its use. Waste Management, v. 33, n. 12, p. 2752-2761, 2013.

CONAMA - Conselho Nacional do Meio Ambiente. Resolução $n^{\circ} 357$ de 17 de março de 2005. Estabelece a classificação das águas doces, salobras e salinas do Território Nacional. Diário Oficial da União, 18 mar. 2005.

CONAMA - Conselho Nacional do Meio Ambiente. Resolução $n^{\circ} 396$ de 03 de abril de 2008. Dispões sobre a classificação e diretrizes ambientais para o enquadramento das águas subterrâneas e dá outras providências. Diário Oficial da União, 07 abr. 2008.

COPAM - Conselho Estadual de Política Ambiental. Deliberação normativa $n^{\circ} 164$ de 30 de março de 2011. Estabelece normas complementares para usinas de açúcar e destilarias de álcool, referentes ao armazenamento e aplicação de vinhaça e águas residuárias no solo agrícola. Diário Oficial da União, 12 abr. 2011.

CORAZZA, R. I. Políticas públicas para tecnologias mais limpas: uma análise das contribuições da economia do meio ambiente. 2001. Tese (Pós-graduação em Política Científica e Tecnológica) - Instituto de Geociências, Universidade de Campinas, Campinas.

EMPRESA BRASILEIRA DE PESQUISA AGROPECUÁRIA - EMBRAPA. Centro Nacional de Pesquisa de Solos. Sistema brasileiro de classificação de solos. Rio de Janeiro, 2006. 306p. 
FEITOSA, Fernando A.C et al. Hidrogeologia conceitos e aplicações. 3 ed. Rio de Janeiro: CPRM/LABHID-UFPE, 2008. 812 p.

FREGOLENTE, L. G.; MIGUEL, T. B. A. R.; de CASTRO MIGUEL, E.; de ALMEIDA MELO, C.; MOREIRA, A. B.; FERREIRA, O. P.; BISINOTI, M. C. Toxicity evaluation of process water from hydrothermal carbonization of sugarcane industry by-products. Environmental Science and Pollution Research, p. 1-11, 2018.

GLOEDEN, E. Monitoramento da qualidade da água das zonas não saturada e saturada em área de fertirrigação com vinhaça. São Paulo: USP, 1994. 115 p. Dissertação Mestrado.

IMASUL - Instituto de Meio Ambiente do Mato Grosso do Sul. Plano Estadua de Recursos Hídricos de Mato Grosso do Sul. Campo Grande, MS: Editora UEMS, 2010. 194 p.

IMASUL - Instituto de Meio Ambiente do Mato Grosso do Sul. Sistema Interativo de Suporte ao Licenciamento Ambiental. Disponível em: <http://www.imasul.ms.gov.br/>. Acesso em: 10 nov. 2012.

KÖPPEN, W.; GEIGER, R. Klimate der Erde. Gotha: Verlag Justus Perthes. 1928. Wall-map $150 \mathrm{~cm} \times 200 \mathrm{~cm}$

LUDOVICE, M. T. F. Estudo do efeito poluente da vinhaça infiltrada em canal condutor de terra sobre o lençol freático. Campinas: UNICAMP, 1997. 117p. Dissertação Mestrado.

LYRA, M. R. C. C.; Rolim, M. M.; Silva, J. A. A. Toposseqüência de solos fertigados com vinhaça: contribuição para a qualidade das águas do lençol freático. Revista Brasileira de Engenharia Agrícola e Ambiental, Campina Grande, v.7, n.3, p.523-532, 2003.

DE MELO, T.R., FERREIRA, R. R. M., NAVROSKI, D., FELTRAN, C. T. M., TAVARES FILHO, J. Physico-chemical attributes of a Cambisol under pasture managed with annual burns after sugarcane vinasse application. International Journal of Recycling of Organic Waste in Agriculture, p. 1-7, 2018.

MINDRISZ, A. C. Avaliação da Contaminação da Água Subterrânea de Poços Tubulares, por Combustíveis Fósseis, no Município de Santo André, São Paulo: Uma Contribuição à Gestão Ambiental, Tese Dr., Instituto de Pesquisas Energéticas e Nucleares/USP, São Paulo, SP, Brasil, 2006.

MOLOZZI, Joseline; PINHEIRO, Adilson; SILVA, Marcos Rivail da. Qualidade da água em diferentes estádios de desenvolvimento do arroz irrigado. Pesq. agropec. bras., Brasília , v. 41, n. 9, Sept. 2006 . Disponível em: <http://www.scielo.br/scielo.php?script=sci_arttext\&pid=S0100204X2006000900007\&lng=en\&nrm=iso>. Acesso em 10 dez. 2012

DE OLIVEIRA BORDONAL, R., CARVALHO, J. L. N., LAL, R., de FIGUEIREDO, E. B., de OLIVEIRA, B. G., LA SCALA, N. Sustainability of sugarcane production in Brazil. A review. Agronomy for Sustainable Development, v. 38, n. 2, p. 13, 2018.
PEREIRA, S.Y.; ARCARO, N. P.; MORTATTI, B.C.; MIGUEL, M.G. Distribuição em profundidade dos elementos químicos em lixiviados de manto de alteração areno silto-argiloso contaminado por vinhaça. Revista Águas Subterrâneas, v. 26, n.1, p. 113-130, 2012.

PIACENTE, F.J. Agroindústria Canavieira e o Sistema de Gestão Ambiental: o caso das usinas localizadas nas Bacias Hidrográficas dos rios Piracicaba, Capivari e Jundiaí. 2005. 181p. Dissertação (Mestrado em Desenvolvimento Econômico) - UNICAMP, Campinas. Disponível em: <http://repositorio.unicamp.br/handle/REPOSIP/286129 >. Acesso em: 12 abr. 2018.

RESENDE, Alexander Silva de et al . Efeito da queima da palhada da canade-açúcar e de aplicações de vinhaça e adubo nitrogenado em características tecnológicas da cultura. Rev. Bras. Ciênc. Solo, Viçosa , v. 30, n. 6, p. 937-941, Dec. 2006. Disponível em: <http://www.scielo.br/scielo.php?script=sci_arttext $\&$ pid=S0100-

$06832006000600003 \&$ lng=en\&nrm=iso>. Acesso em: 12 abr. 2018.

R Core Team. (2017) R: A language and environment for statistical computing. R Foundation for Statistical Computing, Vienna, Austria. URL https://www.R-project.org/, 2017.

ROLIM, M. M.; LYRA, M. R. C. C.; DUARTE, A. S.; MEDEIROS, P. R. F.; SILVA, E. F. F.; PEDROSA, E. M. R. Influência de uma lagoa de distribuição de vinhaça na qualidade da água. Ambi-Agua, Taubaté, v. 8, n. 1, p. 155-171, 2013.

SEMADE - Secretaria Estadual de Meio Ambiente e Desenvolvimento Econômico. Resolução SEMADE No 19 DE 02/09/2015. Estabelece critérios e procedimentos para o armazenamento, a distribuição e a aplicação no solo agrícola, da vinhaça in natura e de águas residuárias geradas a partir do processamento da cana-de-açúcar no Estado de Mato Grosso do Sul e dá outras providências.

SILVA, M. A. S.; GRIEBELER, N. P.; BORGES, L. C. Uso de vinhaça e impactos nas propriedades do solo e lençol freático. Revista Brasileira de Engenharia Agrícola e Ambiental. Campina Grande-PB, v.11, n.1, p. 108-114, 2007. Disponível em: <http://www.scielo.br/pdf/rbeaa/v11n1/v11n1a14.pdf >. Acesso em: 10 jan. 2013.

TABOR, J. A. et. al. Spatial variability of nitrate in irrigated cotton. v. I. Petioles. Soil Science Society of America Journal, v. 48, p. 602-607, 1984.

VON SPERLING, M. Introdução à qualidade das águas e ao tratamento de esgotos: princípios do tratamento biológico de águas residuárias. v. 1. Belo Horizonte: DESA-UFMG, 2005, 452 p.

WAKIDA, F. T.; LERNER, D. N. Non-agricultural sources of groundwater nitrate: a review and case study. Water Research, v. 39, p. 3-16, 2005. Disponível em: < http://www.sciencedirect.com/science/article/pii/S004313540400 452X>. Acesso em: 02 jul. 2013. 